\title{
Defeito ósseo de Stafne em região anterior: relato de caso
}

\author{
The Stafne defect in the anterior region: a case report
}

\begin{abstract}
Eugênio Braz Rodrigues Arantes, ${ }^{1}$ Taiane dos Santos Lopes, ${ }^{1}$ Bárbara Barreto Pacheco Valentim, ${ }^{1}$ Jose Alexandre da Rocha Curvelo, ${ }^{1}$ Fábio Ribeiro Guedes, ${ }^{2}$ Maria Elisa Rangel Janini ${ }^{1,2}$

${ }^{1}$ Especialização em Estomatologia, Departamento de Patologia e Diagnóstico Oral, Faculdade de Odontologia, Universidade Federal do Rio de Janeiro, Rio de Janeiro, RJ, Brasil

${ }^{2}$ Departamento de Patologia e Diagnóstico Oral, Faculdade de Odontologia, Universidade Federal do Rio de Janeiro, Rio de Janeiro, RJ, Brasil

- Os autores declaram que não há conflito de interesse.

\section{Resumo}

Objetivo: este trabalho tem como objetivo relatar um caso raro de defeito ósseo de Stafne, discutindo o diagnóstico, características clínicas, radiográficas e forma de tratamento. Relato de Caso: paciente do sexo feminino, 63 anos de idade, apresentando um defeito radiolúcido em região anterior de mandíbula. Além do exame físico, a paciente foi submetida à radiografia periapical convencional, radiografia panorâmica e tomografia computadorizada do tipo Cone Beam. Diante dos aspectos clínicos, radiográficos e da ausência de sintomas, o diagnóstico foi de defeito ósseo de Stafne. A paciente não foi submetida à cirurgia e segue em acompanhamento clínico e radiográfico de 2 anos. Conclusão: sendo assim, é necessário realizar adequadamente os exames de rotina prévios aos procedimentos cirúrgicos.

Palavras-chave: Defeito ósseo de Stafne; Cistos ósseos; Cistos não odontogênicos.

ABSTRACT

Objective: Objective: we aimed to present a rare case of the Stafne defect and discuss its diagnosis, clinical and radiographic features, and treatment. Case Report: the patient was a 63-year-old woman with a radiolucent defect in the anterior region of the mandible. In addition to physical examination, the patient underwent conventional periapical radiography, panoramic radiography, and cone-beam computed tomography. Due to clinical aspects, radiographic aspects, and absence of symptoms, the Stafne defect was diagnosed. The patient did not undergo surgery and remained under controlled clinical and radiographic monitoring throughout the 2 years of follow-up. Conclusion: it is necessary to perform routine examinations before surgical procedures.

Keywords: The Stafne defect; Bone cysts; Non-odontogenic cysts.
\end{abstract}

\section{Introdução}

$\mathbf{0}$ defeito ósseo de Stafne também chamado de cisto ósseo de Stafne, cisto ósseo latente ou cisto ósseo estático foi descrito como uma lesão radiolúcida assintomática, localizada próximo ao ângulo da mandíbula. ${ }^{1}$ Foi descrito pela primeira vez, em 1942, por Stafne, que relatou 35 lesões radioluscentes, ovoides, com margens ósseas definidas, assintomáticas, localizadas perto do ângulo mandibular, a que chamou de cavidades ósseas situadas no ângulo da mandíbula. ${ }^{2}$

A etiologia e patogenia desse defeito ósseo permanecem incertas. Geralmente, essa condição tem predileção pelo sexo masculino e é observada neste grupo em $80 \%$ a $90 \%$ de todos os casos. ${ }^{1}$ Com incidência na quinta e sexta décadas de vida, envolvendo a mandíbula de forma unilateral e raramente de forma bilateral. Clinicamente, pode apresentar uma interrupção da continuidade da margem inferior da mandíbula e gerar uma depressão palpável nesta área. Não apresenta sintoma e, em geral, o diagnóstico é realizado pelas características clinicas e radiográficas. ${ }^{3}$

Os exames de imagem mais utilizados para o diagnóstico são radiografia panorâmica, tomografia computadorizada e ressonância magnética. ${ }^{4}$ Durante a avaliação por imagem pode-se observar uma imagem típica radiolúcida, unilateral, abaixo do canal alveolar inferior, geralmente entre os pré-molares inferiores e o ângulo da mandíbula, com espessamento do osso cortical e medindo, aproximadamente, de $5 \mathrm{a} 30 \mathrm{~mm} .{ }^{5}$ Uma tomografia computadorizada de feixe cônico proporciona a visualização de uma imagem de forma arredondada, hipodensa, bem delimitada por um halo hiperdenso, sobreposta ao canal mandibular. Ainda pode-se notar uma depressão óssea na cortical lingual do corpo da mandíbula, com limites nítidos e com integridade da cortical óssea vestibular. ${ }^{6}$

A prevalência dos defeitos ósseos de Stafne, descritos na literatura, varia de $0,1 \%$ para $0,48 \% .^{7} \mathrm{E}$, em uma prevalência ainda mais rara e com diagnóstico difícil, essa condição é descrita na região anterior. Nestes casos, está localizada próxima a área de incisivos, caninos ou pré-molares, acima do músculo milo-hioideo e associada à inclusão do tecido da glândula salivar sublingual na mandíbula. ${ }^{1,4}$

No presente artigo é relatado um caso de defeito ósseo de Stafne, assim como foram discutidos o diagnóstico, características clínicas, radiográficas e forma de tratamento, apresentando uma variante rara desta lesão localizada em região anterior de mandíbula.

\section{Relato de Caso}

Paciente do sexo feminino, 63 anos de idade, compareceu ao Serviço de Estomatologia da Faculdade de Odontologia da Universidade Federal do Rio de Janeiro para avaliação de imagem radiolúcida em região anterior da mandíbula esquerda assintomática. Durante a anamnese não foram relatados histórico de trauma ou cirurgias orais pregressas. A imagem foi detectada durante avaliação radiográfica para colocação de implantes dentários. $\mathrm{O}$ profissional responsável solicitou avaliação devido a uma possível contra indicação ao trabalho protético proposto.

Ao exame físico não foi notada nenhuma alteração óssea intra ou extraoral. O exame radiográfico panorâmico demonstrava área radiolúcida bem circunscrita em região anterior mandibular esquerda com limites bem delimitados (figura 1). Na tomografia 
computadorizada do tipo Cone Beam em corte sagital e na reconstrução tridimensional foi possível perceber com melhor detalhamento a depressão óssea (figuras 2 e 3 ).

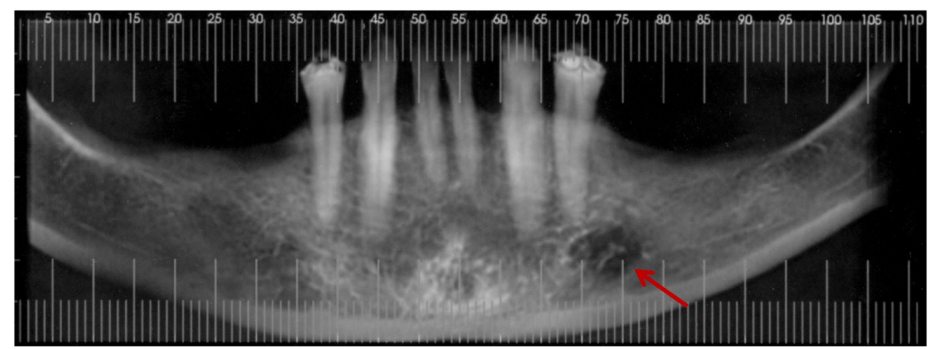

Figura 1. Vista panorâmica apresentando lesão hipodensa no lado esquerdo da mandíbula

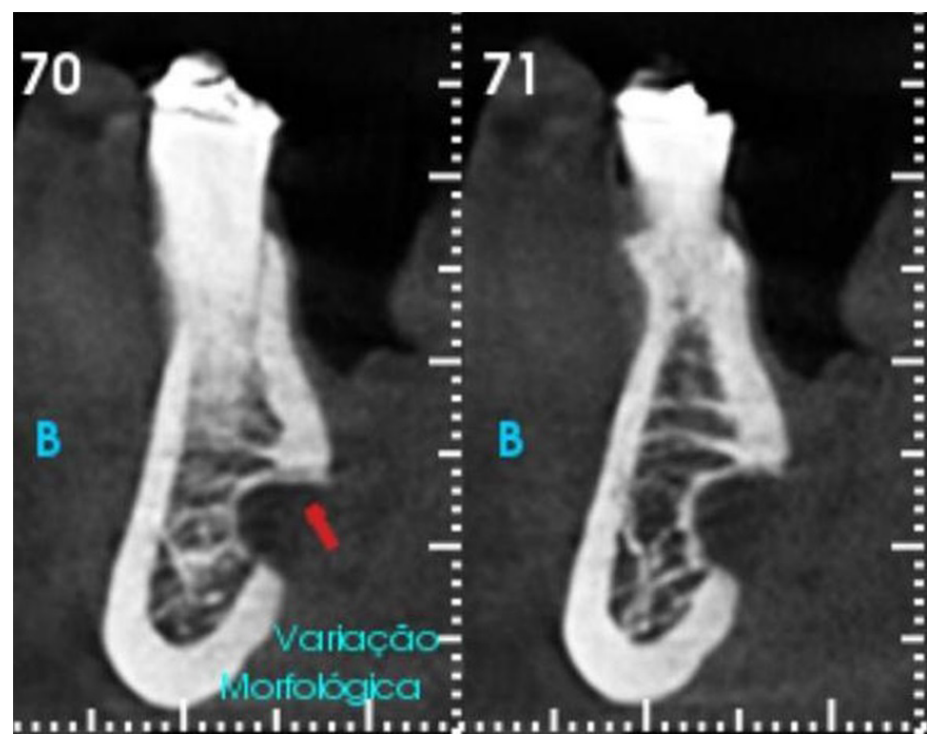

Figura 2. Tomografia computadorizada mostrando lesão na região anterior de mandíbula

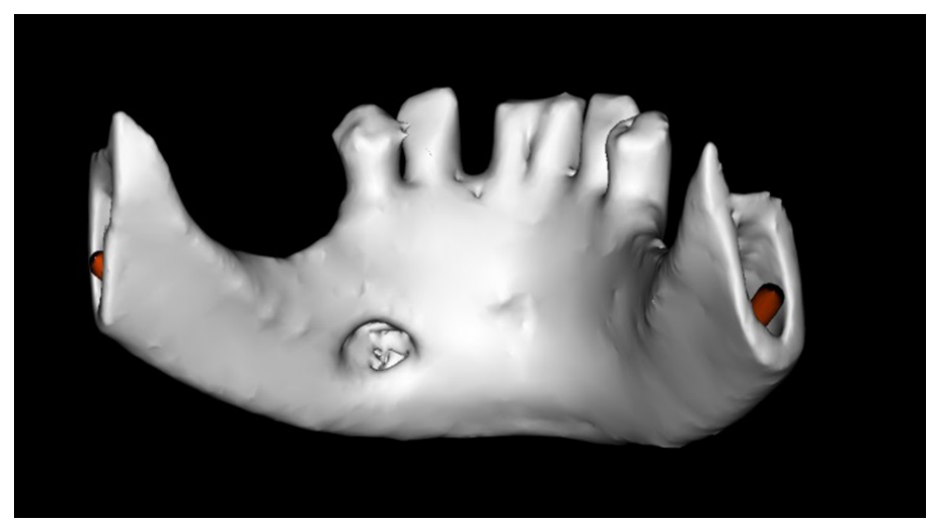

Figura 3. Reconstrução tridimensional de mandíbula para visualização da cavidade óssea na superfície lingual

Baseado no exame físico e de imagem o diagnóstico foi de defeito ósseo de Stafne. Diante deste quadro, não foram necessários procedimentos cirúrgicos, entretanto, o caso segue em acompanhamento de 2 anos com exames radiográficos periódicos sem alterações no defeito. Foi recomendado ao implantodontista que se evitasse a área da alteração óssea durante a reabilitação dentária.

\section{Discussão}

O defeito ósseo de Stafne foi primeiramente descrito por Stafne, em 1942, sendo considerada uma entidade rara. Estudos publicados e baseados em radiografias mostram uma frequência de $0,10 \%$ a $0,48 \% .^{2}$ Porém, em outros estudos fundamentados na observação de mandíbulas secas, esta frequência é ligeiramente maior. Harvey e Noble ${ }^{8}$ encontraram sete cavidades ósseas em 950 mandíbulas $(0,73 \%)$ e Kay ${ }^{9}$ encontrou 11 em 1385 mandíbulas $(1,28 \%)$, esta diferença de frequências, pode estar relacionada com o fato dos casos menores não terem uma visualização radiográfica mais evidente ou que nem todos os indivíduos com esta alteração realizaram exames radiográficos, o que impossibilita o diagnóstico.

Várias hipóteses da etiologia foram propostas, a causa e a patogênese ainda são incertas. A maioria dos autores aceita a hipótese que estas cavidades são congênitas. Outros pensam que elas se desenvolvem mais tarde através da reabsorção por pressão localizada na superfície lingual da mandíbula a partir da glândula salivar adjacente. Stafne sugeriu que a cavidade pode resultar de uma falha de deposição óssea normal na região antigamente ocupada por cartilagem. ${ }^{2,4}$

O conteúdo do defeito ósseo de Stafne tem sido investigado cirurgicamente por diversos autores, que revelaram a presença de tecido glandular dentro do defeito ósseo, no entanto, outros estudos observaram que a depressão óssea estava sendo ocupada por outros tecidos como: linfoide, adiposo, neuromuscular, fibroso ou até mesmo sem qualquer conteúdo. ${ }^{1}$

O sexo masculino é mais afetado (70-90\%), sendo mais frequente na quinta e sexta décadas de vida. ${ }^{10}$ No caso descrito, apesar de se tratar de uma paciente do sexo feminino a idade relatada corrobora com os dados da literatura. Este defeito pode apresentar tamanho variado de $1 \mathrm{a} 3 \mathrm{~cm}$. E sua localização preferencial é a região posterior da mandíbula acima do canal mandibular e em raras ocasiões apresenta-se como uma imagem radiolúcida anterior. ${ }^{1}$

O diagnóstico desta cavidade, geralmente, é realizado através de radiografias de rotina, pois os pacientes não apresentam sinais e sintomas. ${ }^{4}$ A radiografia panorâmica, normalmente, é o exame que identifica em primeiro lugar essa entidade, mostrando uma imagem radiolúcida, com bordas bem definidas escleróticas, situada numa localização posterior da mandíbula, abaixo do canal dentário inferior. Desse modo, devido à típica aparência e localização das cavidades, o diagnóstico é frequentemente baseado nas radiografias panorâmicas e periapicais. ${ }^{5}$ Além das radiografias convencionais, pode-se utilizar outros recursos de imaginologia, como a sialografia, a tomografia computadorizada e imagem por ressonância magnética. ${ }^{6}$

Alguns autores relatam que o tratamento pode ser baseado em duas opções terapêuticas, a intervenção cirúrgica ou o acompanhamento, sendo a última preferível, através de controles clínicos e radiográficos. ${ }^{2,4}$ No caso relatado, não foi necessária intervenção cirúrgica uma vez que os dados apresentados pelos exames físico e radiográfico eram satisfatórios para o diagnóstico, além disso, a 
paciente era assintomática e não demonstrava sinais clínicos.

A variante anterior do defeito ósseo de Stafne é rara, mas apresenta uma gama de diagnósticos diferenciais. Antes de programar procedimentos cirúrgicos ou exploratórios, o exame físico da face e da mucosa oral foi realizado minuciosamente e associado aos exames de imagem que auxiliaram no diagnóstico desta lesão. Conforme o trabalho exposto por Deyhimi et al. ${ }^{4}$ e no nosso caso clínico, a cirurgia não é indicada a não ser nos casos de outras lesões suspeitas como cistos ou tumores.
O defeito ósseo de Stafne é observado em radiografias convencionais de pacientes assintomáticos, o que mostra a importância da realização destes exames para o diagnóstico preciso, evitandose procedimentos cirúrgicos desnecessários ou intervenções de reabilitação protética na área envolvida. Além disso, atualmente, devido ao crescente desenvolvimento das técnicas de imagem, e ao caráter estático e benigno da lesão, o uso de controles clínico e radiográfico é, sem dúvida, o mais adequado.

\section{Conclusão}

\section{Referências}

1. Neville BW, Damm DD, Allen CM, Bouquot J. Oral and maxillofacial pathology. 3rd ed. Philadelphia: WB Saunders; 2008.

2. Stafne EC. Bone cavities situated near the angle of the mandible. J Am Dent Assoc. 1942;29:1969-72.

3. Barker GR. A radiolucency of the ascending ramus of the mandible associated with invested parotid salivary gland material and analogous with a Stafne bone cavity. Br J Oral Maxillofac Surg. 1988;26:81-4.

4. Deyhimi P, Darisavi S, Khalesi S. Stafne bone cavity with ectopic salivary gland tissue in the anterior of mandible. Dent Res J (Isfahan). 2016; 13(5): 454-57.

5. Assaf AT, Solaty M, Zrnc TA, Fuhrmann AW, Scheuer H, Heiland M, et al. Prevalence of Stafne's bone cavity--retrospective analysis of 14,005 panoramic views. In Vivo. 2014;28(6):1159-64.
6. Shimizu M, Osa N, Okamura K, Yoshiura K. CT analysis of the Stafne's bone defects of the mandible. Dentomaxillofac Radiol. 2006;35(2):95-102.

7. De Courten A, Küffer R, Samson J, Lombardi T. Anterior lingual mandibular salivary gland defect (Stafne defect) presenting as a residual cyst. Oral Surg Oral Med Oral Pathol Oral Radiol Endod. 2002;94:460-4.

8. Harvey W, Noble HW. Defects on the lingual surface of the mandible near the angle. Br J Oral Surg. 1968;6:75-83.

9. Kay LW. Some anthropologic investigations of interest to oral surgeons. Int J Oral Surg. 1974;3:363-379.

10. Quesada-Gómez C, Valmaseda-Castellón E, Berini-Aytés L, Gay-Escoda C. Stafne bone cavity: a retrospective study of 11 cases. Med Oral Patol Oral Cir Bucal. 2006;11:E277-280.

\section{Mini Currículo e Contribuição dos Autores}

1. Eugênio Braz Rodrigues Arantes - cirurgião-dentista e especialista em Estomatologia. Contribuição: concepção e desenho do trabalho, revisão da literatura, condução do caso clínico, elaboração e edição do manuscrito.

2. Taiane dos Santos Lopes - cirurgiã-dentista e especialista em Estomatologia. Contribuição: revisão da literatura e acompanhamento do caso clínico.

3. Bárbara Barreto Pacheco Valentim - cirurgiã-dentista e especialista em Estomatologia. Contribuição: revisão da literatura e acompanhamento do caso clínico.

4. Jose Alexandre da Rocha Curvelo - cirurgião-dentista e especialista em Estomatologia. Contribuição: revisão da literatura, fotografias, coleta de dados e acompanhamento do caso clínico.

5. Fábio Ribeiro Guedes - cirurgião-dentista e professor Adjunto de Radiologia do Departamento de Patologia e Diagnóstico Oral da Universidade Federal do Rio de Janeiro. Contribuição: acompanhamento do caso clínico, aquisição, análise e interpretação de dados dos exames de imagem.

6. Maria Elisa Rangel Janini - cirurgiã-dentista e professora Adjunta de Estomatologia do Departamento de Patologia e Diagnóstico Oral da Universidade Federal do Rio de Janeiro. Contribuição: concepção e desenho do trabalho, condução do caso clínico, elaboração e edição do manuscrito, revisão crítica do manuscrito.

Recebido em: 17/01/2017 / Aprovado em: 03/02/2017

Autor Correspondente

Eugênio Braz Rodrigues Arantes

E-mail: ebarantes@gmail.com 